\title{
Integrated Development of a Region Based on Foreign and Russian Experience in the Implementation of Cluster Initiatives
}

Oksana Vitalievna Dmitrenko

Ekaterina Aleksandrovna Zhalsaraeva

Marina Abramovna Dugarzhapova

Department of Finances and Credit, East-Siberian State University of Technology and Management, Ulan-Ude, Russian Federation Correspondence: Oksana Vitalievna Dmitrenko, Department of Finances and Credit, East-Siberian State University of Technology and Management, Ulan-Ude, Russian Federation. E-mail: dmitrenko_oksana@inbox.ru, katya1e@yandex.ru

\author{
Doi:10.5901/mjss.2015.v6n5s4p356
}

\section{Abstract}

Against the background of the efforts of Russian regions to achieve economic growth, sustainable exploitation of the resource potential for self-development and substitution of the import of goods, the production of which can be organized using their own raw materials and logistical base, a long-term approach to comprehensive development with account of the geographical and socioeconomic situation, environmental limitations, and possible competitive advantages of territories, is needed. Based on the experience of countries and regions, the authors have analyzed the prerequisites and trends in the development of innovative and regional industrial clusters in the regions of Russia. They substantiate the prospects of creating regional industrial clusters in regions with the poorly exploited resource potential. Taking into account the environmental and economic constraints, competitive advantages, and market opportunities for the exploitation of the existing resources in the Republic of Buryatia, the authors develop the lines and methods of sustainable development of the agri-food cluster in this region.

Keywords: region's resources, comprehensive development of a territory, governmental and regional cluster policy, innovation clusters, regional industrial clusters, the agri-food cluster of the Republic of Buryatia

\section{Introduction}

During 2000-2015, the market economy development in Russia has involved finding and implementing effective solutions to ensure economic growth based on the rational use of the country's resources and the production of globally competitive products. Programs of innovative development of companies were being developed, national technology platforms were being formed, and high-tech production was being organized.

The pace of the economic growth in Russia in the early 2000 exceeded $10 \%$, and in the following years, the rate of Russia's GDP growth was gradually slowing down. The reason was that until then, the country had not formed a business environment for the development and dissemination of innovations.

Distribution of innovatively active companies able to attract investors remains extremely uneven in Russia. The leading regions are the donors of peripheral regions, where the economy still rests on the legacy of Soviet Russia.

There is a need to identify the reserves for regions' development, to form a system of rational exploitation of the resource potential, to create conditions for the development of entrepreneurship, provide a favorable climate for innovation and investors attraction.

Achievement of an acceptable level of production of high quality goods and services and solution of the problem of import substitution in Russia are impossible without the entrepreneurship development in all regions with account of the geographical and socioeconomic situation, the environmental constraints, and the competitive advantages of territories.

Foreign experience of development shows that cluster initiatives in business development, which involve cooperation between enterprises, research centers, and educational institutions supported by the government, contribute to creating positive conditions for the development of innovations, the dissemination of knowledge and technology, and the business activity.

Clusters are aimed at consolidating the efforts of all participants in the development and implementation of joint projects, and at strengthening the market positions. Producing competitive products and services, clusters become the "points of growth" of regions, gradually integrating an increasing number of market players into the business process. The 
increased competition causes the development and dissemination of knowledge, the search for new ideas, the development of projects and technologies capable of ensuring the innovative development and efficient use of resources in a region. Following the above, cluster policy is becoming the most demanded tool for development of the economy of regions and entire Russia.

\section{Foreign Cluster Initiatives: The Implementation Experience, the State Support Organization}

Specifying foreign experience in implementing cluster initiatives, we need to note that the cluster policy is implemented in the European Union, the USA, Canada, Japan, and China.

The EU takes various steps to increase the innovativeness of the European industry. The EU considers cluster policy as a key tool to enhance the competitiveness of industries and regions, the innovative capacity, and the economic development in the medium and long term (Competitiveness clusters in France).

The European experience shows that small and medium-sized enterprises are the key players in the cluster programs implemented by the government. The model programs for a number of countries are the cluster initiatives development programs: InnoRegio (Germany) and Competitiveness Clusters (France). The majority of companies participating in the InnoRegio (Germany) program are small and medium-sized companies; so are $80 \%$ of companies participating in the cluster program Competitiveness Clusters in France.

According to the Competitiveness Clusters program (France), all French regions (22 in total) received a single technical specification for the creation of "competitiveness poles" (clusters) with an essential condition to engage three types of members-the business, the scientific community, and educational structures; to have their own strategy, not contrary to the regional development strategy, and a developed plan of objectives and efforts for three years, as well as a developed organizational structure. The status of the "competitiveness pole" is to be confirmed every 3 years (Competitiveness clusters in France).

In the US state of Arizona, with the participation of the M. Porter's Center, a program of strategic partnership for economic development was developed. In the result, nine models of clusters were identified. The activities during 19911999 demonstrated the ability of the clusters for survival and improvement.

The clustering of the economy of Turkey has been implemented since the early 1990s and has become popular in almost every region of the country. The specificity of cluster development of the majority of regions is that mainly low or medium technology clusters with high intensity of low-skilled labor were formed there. It resulted in a relatively large number of clusters for the production of textiles, clothes, shoes, food, packaging, and souvenirs. Only five key regionsIstanbul, Ankara, Izmir, and Bursa-have managed to create unique production types in two high-tech clusters.

China has mainly developed various sectoral clusters. The result of investment of about 20 billion dollars in China's automotive industry was the formation of automotive clusters with a wide network of suppliers across the country, a research base, engineering companies, and centers for the development of innovations (Skoch, 2014).

Within the framework of the governmental cluster policy of the leading countries, a broad range of mechanisms and tools is used to support and encourage the development of regional clusters, including the creation of specialized coordination, advisory, and working bodies, the institutional and expert-analytical support of the development of regional clusters, the direct state co-financing of programs and projects of regional clusters development.

The US Federal Government, in order to coordinate the activities of various federal executive bodies in the field of cluster policy, established the Federal Task Force on Regional Innovation Clusters. Also, interdepartmental coordination bodies at various times were established in Finland, France, Norway, and Sweden (Clusters for competitiveness. A Practical Guide \& Policy Implications for Developing Cluster Initiatives).

Under the auspices of the European Commission, a number of organizations were established to provide regional clusters with the support in information, education, counseling, and marketing-the European Cluster Observatory, the European Cluster Policy Group, the European Cluster Alliance, and the Cluster Innovation Platform.

In order to provide the organizational and expert-analytical support for the development of regional clusters, regular scientific and research work is implemented under the auspices of the European Commission. Also, the development of regional clusters is regularly monitored (for example, within the ERAWATCH-INNO-Policy TrendChart database) (Pro inno Europe).

\section{Regional Clusters in Russia: Government Initiatives, Centers of Cluster Development, Government Support}

Development of cluster initiatives in Russia is enshrined in the Concept of Long-Term Socioeconomic Development of the Russian Federation until 2020. The possibility of modernization of the economy and the implementation of the competitive 
potential of regions is associated with the creation of regional industrial clusters. Differentiation of Russian regions by the level of innovative and socioeconomic development involves the implementation of two types of clusters: 1- innovative (high-tech) and regional industrial clusters.

In 2012, a list of innovative regional clusters in Russia was approved, which includes 25 regional clusters determined through competitive selection (Ministry of Economic Development of the Russian Federation, 2012).

The program provides for the creation of innovation clusters in all federal districts of the country, but the number of projects is distributed unevenly (Figure 1).

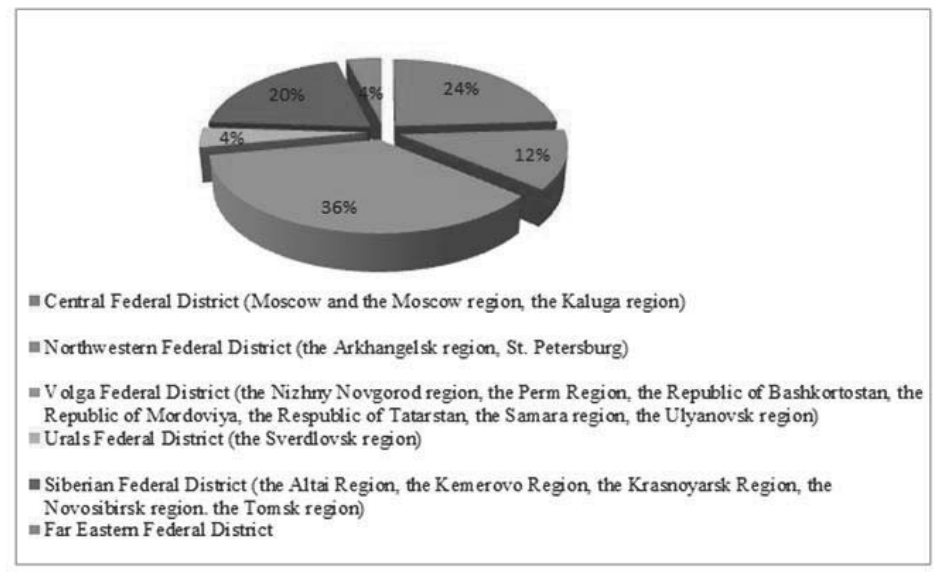

Figure 1. Distribution of the pilot innovation clusters in the regions of Russia (\%)

Application of the tools of clusters development at the national level is offered only in the industrialized regions of the country. The main specialization of clusters is the production that has a strong competitive position in the world market: nuclear technology, information and communication technology, aircraft and spacecraft production, oil and gas processing, and petrochemical industry.

The tools for promoting cluster projects are federal targeted programs, State Programs of the Russian Federation, and non-budgetary funds. A key role is assigned to governmental institutions-RUSNANO, the Russian Foundation for Technological Development, and the Center for Development and Commercialization of New Technologies "Skolkovo" (Ministry of Economic Development of the Russian Federation).

The unequal distribution of innovative clusters in the territory of the Russian Federation regions is obvious (Figure 2) (Pilot innovative territorial clusters in Russia. Moscow: National Research University "Higher School of Economics", 2013).

For example, in the Siberian Federal District, the list does not include projects of the Republic of Buryatia, the Republic of Tyva, the Republic of Khakassia, the Trans-Baikal, Irkutsk, and Omsk Regions, the total area of which covers $2,039.2 \mathrm{~km}^{2}, 40.3 \%$ of the Siberian Federal District and 12\% of Russia (Passports of subjects of the Russian Federation in the Siberian Federal District). In the Far Eastern Federal District, only the Khabarovsk Region was included in the list of subjects of cluster development.

For these regions that have a poorly developed resource potential, the development of cluster initiatives is proposed within the framework of regional development programs (Guidelines for the implementation of the cluster policy in the northern regions of the Russian Federation. Website of the Chamber of Commerce and Industry of the Russian Federation). 


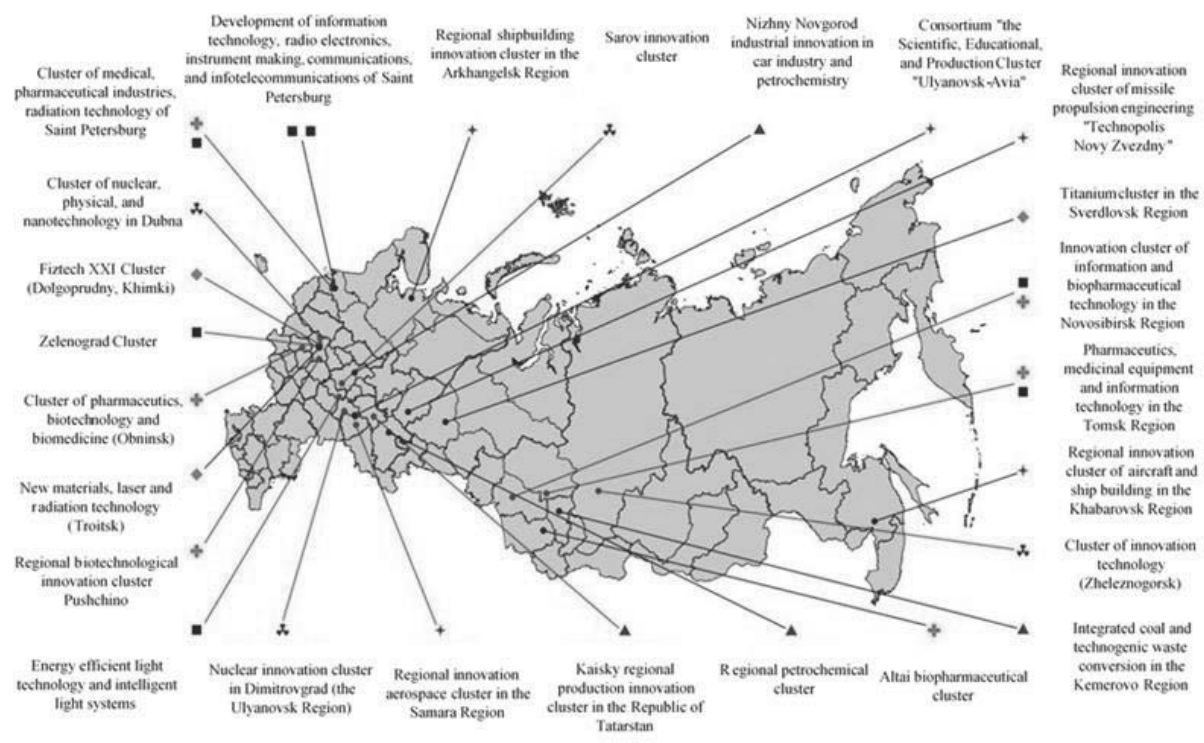

Figure 2. Map of Russian innovation clusters (Pilot innovative territorial clusters in Russia. Moscow: National Research University "Higher School of Economics", 2013).

\section{Formation of the Cluster Form of Resources Exploitation in the Republic of Buryatia}

The Republic of Buryatia is a subject of the Russian Federation and is included in the Siberian Federal District. The distance from the capital of Russia is $5,519 \mathrm{~km}$. In the Republic of Buryatia, the economic situation is characterized by the presence of certain factors of competitiveness: the natural resource potential including the unique reserves of mineral resources, the water and other recreational resources of Lake Baikal, the forest resources, a large quantity of agricultural land, the presence of the complex of scientific and educational institutions that can train personnel for the development of regional clusters.

To date, there are a number of significant limitations to the development of regional industrial clusters in the region: the low level of income and living standards, insufficient domestic demand, a high level of population's loans, weak entrepreneurial initiative and non-readiness of the business for innovations, and an imperfect competitive environment.

Analyzing the situation with the development of cluster initiatives in the Republic of Buryatia, we are trying to determine the actually implemented regional industrial clusters that can generate the growth points of the regional production and supply local products of high quality to the market of the Republic of Buryatia.

The principal aim of the regional industrial clusters development is to develop the regional production based on the exploitation of natural resources, create competitive regional production, and bring the products to the local market and the population. Buryatia.

First, let us formulate a clear definition of a regional industrial cluster oriented to the market of the Republic of

A regional industrial cluster is the formed within the framework of the regional cluster policy self-organization of economic agents, including industrial, auxiliary, and service enterprises carrying out their own activities in a competitive environment within a limited area, provided the economic and social interests of all members of the cluster are met and their innovative development is ensured.

The Strategy of Socioeconomic Development of the Republic of Buryatia until 2025 implements the scenario of "Innovative Sustainable Development" as the only acceptable and supported one. It involves gradual increase in the production of competitive products with high added value, including the deep processing of extracted raw materials (Resolution of the Government of the Republic of Buryatia "On the Strategy of socio-economic development of the Republic of Buryatia until 2025", 2007). 
Originally, three clusters were given the priority, which are concentrated mainly in the territory of the Republic of Buryatia, and for the development of which the region has tools, authority, and resources: The agri-food cluster, the tourism cluster, and the construction and construction materials cluster.

Having a unique natural object in its territory-Lake Baikal-the Republic of Buryatia bears almost all costs associated with the implementation of environmental functions. Herewith, Lake Baikal is a UNESCO's World Natural Heritage Site. Over $80 \%$ of the catchment area of Lake Baikal falls on the Republic of Buryatia, and the restrictions imposed by the special regime of economic activity, cover almost the entire territory of the republic (Resolution of the Government of the Republic of Buryatia "On the Strategy of socio-economic development of the Republic of Buryatia until 2025").

Referring to the international experience in implementation of cluster initiatives, we emphasize that small and medium-sized enterprises are the main beneficiaries of the cluster programs implemented by the government.

We find this idea the most efficient for the implementation of cluster initiatives in the Republic of Buryatia, because small and medium-sized enterprises can most flexibly combine the development of production and non-pollution of the environment.

\section{The Agri-Food Cluster of the Republic of Buryatia: Specialization, Opportunities and Risks of Formation, and Sustainable Development Efforts}

The use of cluster forms of the agricultural production organization in the territory of the republic will form the necessary transition from the anthropogenic development to organic agricultural production, which is of particular relevance for the Baikal region. It is possible to establish production at small and medium-sized enterprises (farms) in the districts of the republic in harmony with the nature, minimize the environmental pollution, and use energy-saving technology.

Creation of agricultural clusters in the districts of the republic will allow ensuring the uniform development of the agricultural production in the most efficient and environmentally careful way, create conditions for the synergistic social effect in rural areas, and preserve the traditional animal breeding and horticulture sectors, the lifestyle, culture, and identity of the rural areas of the Republic of Buryatia.

West Zone: sheep and horse breeding, potato growing

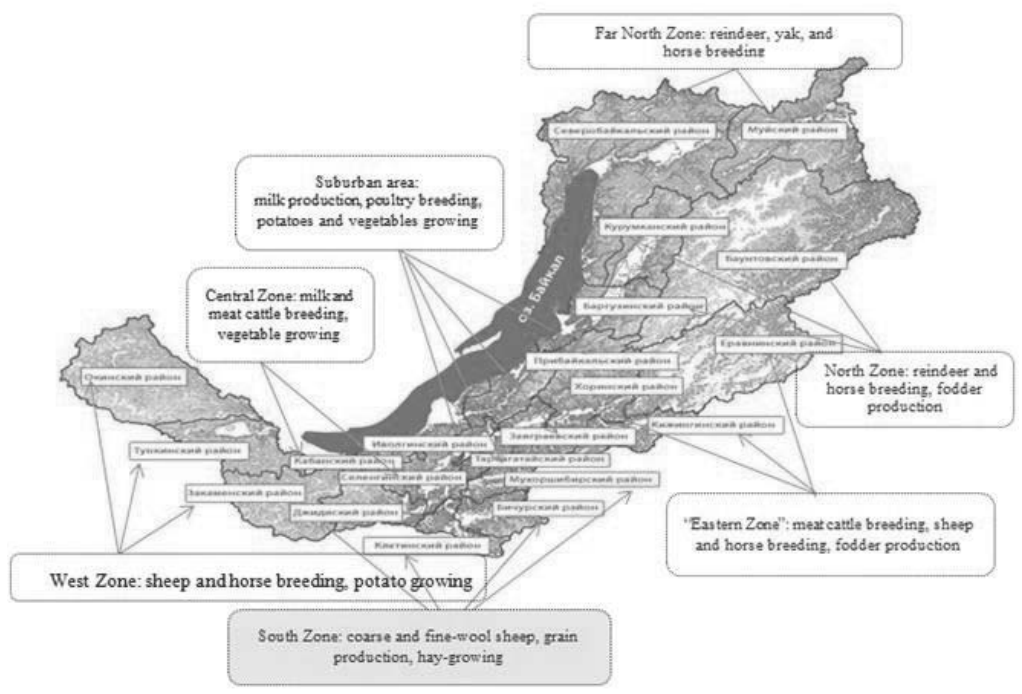

Figure 3. Map of the specialization areas of the agri-food clusters of the Republic of Buryatia

Agri-food clusters suggest specialization of the republic districts:

- The "Suburban Zone": production of grain, potatoes and vegetables growing, dairy cattle and poultry breeding;

- The "Central Zone": production of grain, potatoes and vegetables growing, dairy and beef cattle breeding; 
- The "Southern Zone": production of grain, potatoes, coarse and fine-wool sheep breeding, dairy and beef cattle breeding;

- The "Western Zone": production of grain and forage, beef cattle, sheep, and horse breeding;

- The "Far North Zone": production of forage, horse, reindeer, and yak breeding;

- The "Northern Zone": forage and grain production, horse, reindeer, and cattle breeding;

- The "Eastern Zone": grain production (for animal feed), fodder production, sheep and horse breeding (The concept of the national territorial and sectoral division of the Republic of Buryatia).

Creation of an agricultural cluster will have an economic, social, and environmental effect on the republic (Figure 4).

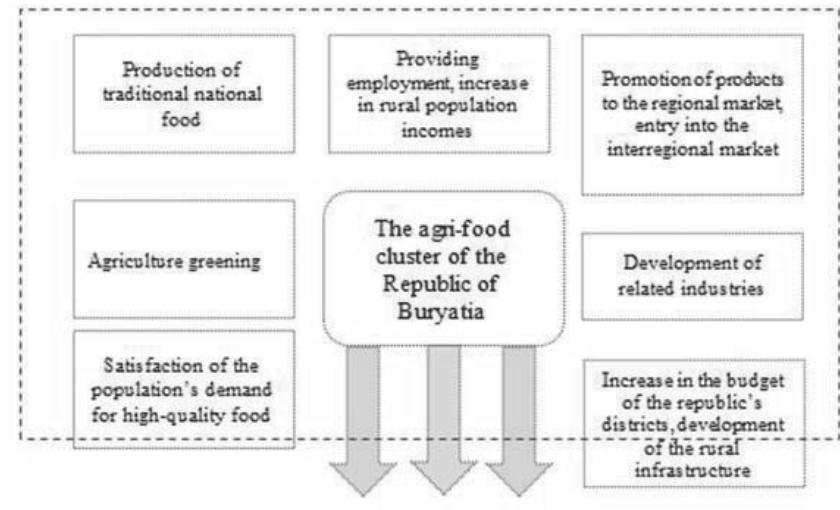

\begin{tabular}{|c|c|c|}
\hline $\begin{array}{c}\text { Environm ental } \\
\text { effect }\end{array}$ & $\begin{array}{c}\text { Socioeconomic } \\
\text { effect }\end{array}$ & $\begin{array}{c}\text { Achievem ent of } \\
\text { sustainable } \\
\text { developm ent of the } \\
\text { cluster }\end{array}$ \\
\hline
\end{tabular}

Figure 4. Environmental and socioeconomic impact of agri-food cluster development in the Republic of Buryatia

The development of the agri-food cluster will be effective in identifying and accounting for the peculiar features of the region: the development of business, geographic location, investment climate, national traditions, availability of scientific and educational centers, and development of the market infrastructure (Table 1).

Table 1. The SWOT-analysis of the agri-food cluster formation in the Republic of Buryatia (Passports of subjects of the Russian Federation in the Siberian Federal District) (Resolution of the Government of the Republic of Buryatia "On approval of the Republican target program to create favorable conditions for attracting investments in the Republic of Buryatia in 2011-2020 "Buryatia-the territory of investments", 2011)

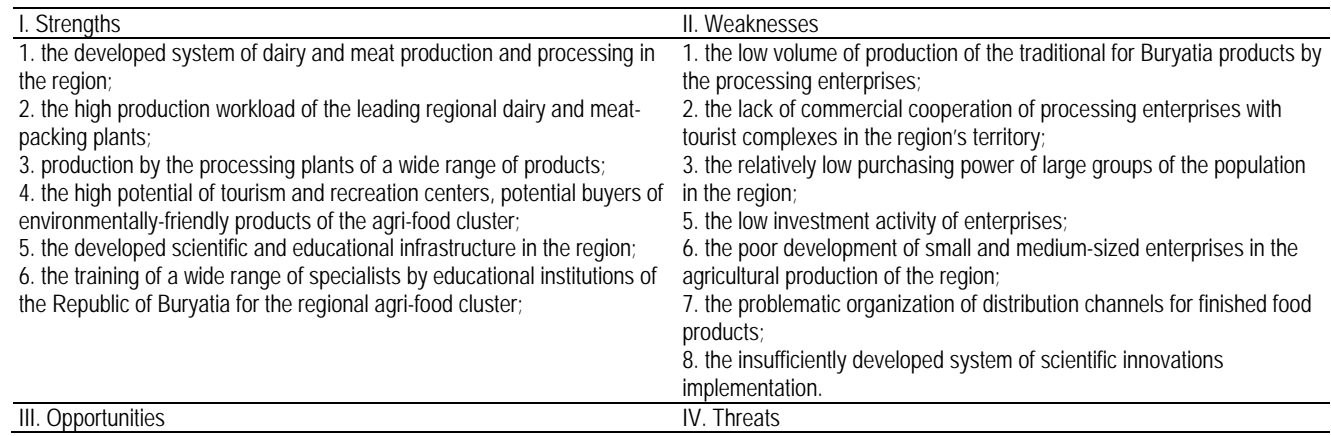


1. stabilization of the livestock and productivity of farm animals

2. increase in the production of environmentally friendly products

3. expansion of the domestic market due to the natural population growth

4. expansion of the distribution channels through the development of the tourism market

5. active development of fair trade in the region;

6. development of competitive industries that combine innovations and traditions of the region (sheep, yak, reindeer, and horse breeding);

7. high quality, environmentally friendly products are elastic goods.

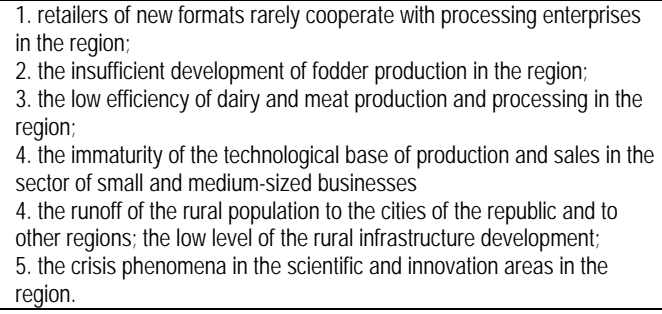

2. the insufficient development of fodder production in the region;

3. the low efficiency of dairy and meat production and processing in the region;

4. the immaturity of the technological base of production and sales in the sector of small and medium-sized businesses

4. the runoff of the rural population to the cities of the republic and to other regions; the low level of the rural infrastructure development; 5. the crisis phenomena in the scientific and innovation areas in the region.

The strengths and weaknesses, the market threats and opportunities were the basis for the determination of the key positions of the formation of the agri-food cluster in the Republic of Buryatia:

- The creation of conditions for the implementation of entrepreneurial initiatives, the development of small and medium-sized businesses in rural areas of the republic;

- The encouragement of the development of cooperative and integrated establishments for the formation of the agri-food cluster;

- Development of the marketing infrastructure, as well as the infrastructure for primary processing, refining, storage, and transportation of agricultural products;

- Support for the cooperative forms of interaction of small businesses regarding the accessibility of financial resources, attraction of investment, and participation in national, regional, and municipal programs and projects implemented within the framework of cluster policy;

- Ensuring access to and dissemination of knowledge, implementation of innovations, attraction of qualified staff to enterprises of the agricultural production and processing industry;

- Promotion of environmentally friendly products to the markets of the region, including through agricultural fairs and cooperative bazaars;

- Development of the sale of products produced by traditional Buryat recipes, in tourist complexes and recreational centers of the Republic of Buryatia.

The background for the agri-food cluster in the Republic of Buryatia should be comprehensively and consistently developed ensuring sustainable development of the cluster.

The effective methods of ensuring sustainable development of the agri-food cluster in the Republic of Buryatia are shown in Figure 5.

The result of the implementation of the proposed methods will be the creation of basic conditions for the development of the agri-food cluster of the Republic of Buryatia:

- The cluster formation integrity;

- Unified technology standards of operation and rational schemes of interaction with business partners;

- A clear management hierarchy;

- Complete and uninterrupted supply of essential resources produced in Russia,

- Economic interest of all participants;

- Synergistic effect of the association;

- Diffusion of knowledge;

- Innovative activity;

- Intensity of the economic development of the region.

The agri-food cluster of the Republic of Buryatia is a constantly evolving system, able to accelerate or slow down the pace of development at different time stages. It is important to reduce the risk of recession and loss of prospects of cooperation by continuous monitoring, responsive and timely adjustment of projects. In the implementation of the cluster policy, the regional authorities should rely on feedback and have communication platforms for a dialog with the business. This will allow effectively and timely take decisions, make adjustments to the programs and projects that would meet the needs of the agri-food cluster of the republic. 


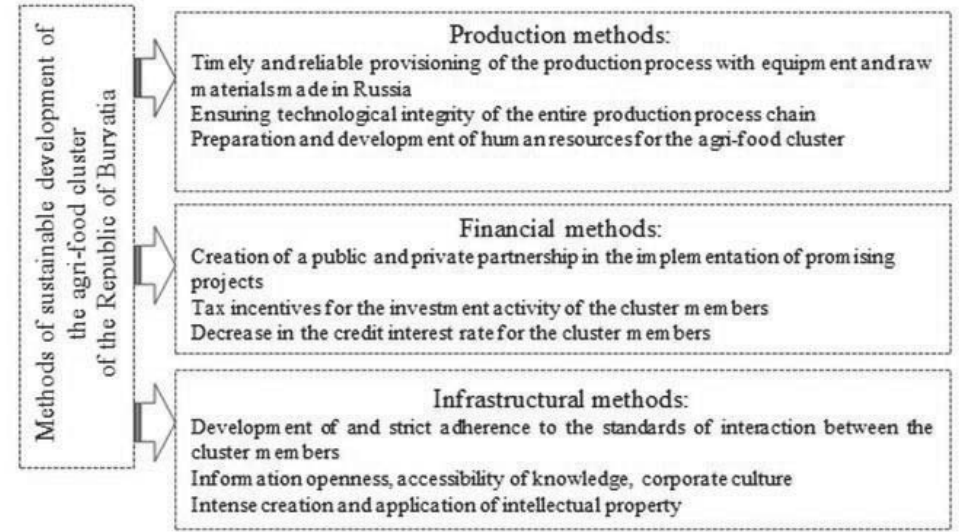

Figure 5. The methods of sustainable development of the agri-food cluster of the Republic of Buryatia

\section{Conclusion}

The theoretical and practical experience in clustering regional economies in foreign countries and advanced regions of Russia allows vigorously implement cluster initiatives for the development of the outermost regions with a poorly exploited resource potential. The concept of long-term development of Russia creates outlines for design of the regional development policy. Regions of Russia are able to determine priorities and really implemented cluster initiatives, and to develop regional cluster policy without assistance.

For the Republic of Buryatia, the formation of the agri-food cluster is a priority task. There is a complete set of resources and authority for implementation of the project. Since 2008, the "Strategy of Socioeconomic Development of the Republic of Buryatia until 2025" emphasizes the agri-food cluster as the most realistically attainable result of the regional cluster policy.

The above article presents the base ideas for the formation of the agri-food cluster and its long-term sustainable development. The full range of actions needed to create the conditions for the development of the cluster is included in the regional cluster policy. Its flexibility, adaptability, and sensitivity to changes in the market environment and the development needs of the cluster interactions will ensure a real transition to the cluster form of exploitation of the resources of the Republic of Buryatia.

\section{Acknowledgements}

This research project was supported by the grant "Young scientists ESSUTM-2015".

\section{References}

Bogdanova, O. V., \& Nikonorova, O. S. (2012). Methodical aspects of formation of a regional agricultural cluster. Rossiyskoe Predprinimatelstvo, 19(217), 139-144.

Clusters for competitiveness. A Practical Guide \& Policy Implications for Developing Cluster Initiatives. Retrieved from http://site resources.worldbank.org

Competitiveness clusters in France. Retrieved from http://www.industrie.gouv.fr/poles-competitivite/brochure-en.html

Emelyanov, S. (2002). The strategy of science and technology in the United States in the XXI century. Problemy Teorii i Praktiki Upravleniya, 1. Retrieved from http://www.inti.kz

Filippov, P. (2006). Clusters of competitiveness-the experience of cluster development in Finland. Proceedings of the portal site for small and medium-sized businesses. Retrieved from http://subcontract.ru

Guidelines for the implementation of the cluster policy in the northern regions of the Russian Federation. Website of the Chamber of Commerce and Industry of the Russian Federation. Retrieved from http://www.tpprf.ru

Guidelines for the implementation of the cluster policy in the Russian Federation: The Letter of the Ministry of Economic Development of the Russian Federation dated December 26, 2008 (No. 20615-AK/D19).

The concept of the national territorial and sectoral division of the Republic of Buryatia. Retrieved from http://www.sibran.ru/ 
Ministry of Economic Development of the Russian Federation. Retrieved from http://economy.gov.ru/minec/activity/sections/ innovations/politicl

Resolution of the Government of the Republic of Buryatia on December 11, 2008 No. 529. On approval of the Concept of development of agriculture and rural areas in the Republic of Buryatia in the years 2009-2017 and for the period up to 2020.

Potravnoy, I. M. (Ed.). (2010). Organic farming on the way to the reality (p. 191). Moscow: Economy.

Passports of subjects of the Russian Federation in the Siberian Federal District. Retrieved from http://www.sibfo.ru/passport/region.php? action=art\&nart=14

Hochberg, L. M., \& Shadrin, A. E. (Eds.). (2013). Pilot innovative territorial clusters in Russia (p. 108). Moscow: National Research University "Higher School of Economics."

Porter, M. E. (2003). Competition (p. 496). Moscow: Williams.

Pro inno Europe. Retrieved from http://proinno.intrasoft.be/index.cfm?fuseaction=wiw.measures\&page=detail\&ID=8922

Resolution of the Government of the Republic of Buryatia on 15.06.2011 No. 295. On approval of the Republican target program to create favorable conditions for attracting investments in the Republic of Buryatia in 2011-2020 "Buryatia-the territory of investments".

Resolution of the Government of Russia dated August 30, 2001 No. 643. On approval of the list of activities prohibited in the central ecological zone of the Baikal natural territory (as amended by the Decree of the Government of Russia dated March 2, 2015).

Resolution of the Government of the Republic of Buryatia dated 15.12.2007 No. 410. On the Strategy of socio-economic development of the Republic of Buryatia until 2025. Retrieved from http://img.rg.ru/pril/92/24/12/strategiya.pdf

Rudnev, P. S. (2007). The experience of creating structural clusters in developed countries. Ekonomika Regiona, 18.

Skoch, A. (2014). The international experience of cluster formation. Materials $f$ the Intelros website. Retrieved from: http://www.intelros.ru 